\title{
A Mutation in NPAS3 That Segregates with Schizophrenia in a Small Family Leads to Protein Aggregation
}

\author{
Leslie G. Nucifora ${ }^{a}$ YeeWen Candace Wu ${ }^{a}$ Brian J. Lee ${ }^{a}$ \\ Li Sha $^{\mathrm{b}}$ Russell L. Margolis ${ }^{\mathrm{a}}$ Christopher A. Ross ${ }^{\mathrm{a}} \quad$ Akira Sawa $^{\mathrm{a}}$ \\ Frederick C. Nucifora Jra \\ ${ }^{a}$ Department of Psychiatry, Johns Hopkins University School of Medicine, Baltimore, Md., USA; \\ ${ }^{\mathrm{b}}$ Department of Biotechnology, Dalian Medical University, Dalian, China
}

\section{Key Words}

Proteostasis · Protein misfolding · Protein aggregation •

Protein quality control · Schizophrenia · NPAS3 · DISC1

\section{Abstract}

Schizophrenia and other major mental illnesses result from a complex interplay of genetic and environmental factors. We previously identified a mutation in NPAS3 that results in a valine to isoleucine (V304I) amino acid substitution segregating with schizophrenia in a small family. The amino acid change occurs in a potentially critical region for protein function. Furthermore, the same amino acid substitution in proteins related to familial Alzheimer's disease and transthyretin amyloidosis has been associated with protein aggregation. In this study, we demonstrate that NPAS3 is prone to aggregation, and that the V304I mutation in NPAS3 increases this propensity in both bacterial and mammalian expression systems. We also show that NPAS3-V304I reduces soluble endogenous NPAS3, and increases insoluble endogenous NPAS3 and leads to alteration of transcriptional activity. These results suggest that protein aggregation, potentially leading to cell dysfunction via a loss of protein function through sequestration, may contribute to the pathogenesis of schizophrenia and other forms of mental illness. Further exploration of the mechanisms leading to abnormal protein quality control could lead to new therapeutic targets.

(c) 2016 S. Karger AG, Basel

\section{Introduction}

Schizophrenia, a devastating disorder that affects up to $1 \%$ of the population [1], is characterized by positive symptoms (such as hallucinations, delusions, and thought disorder), negative symptoms (including affective flattening, poor social interaction, and lack of motivation), and cognitive decline. The etiology of schizophrenia is complex and incompletely understood, but most cases appear to arise from a combination of genetic variants acting in concert [2-4] together with environmental factors $[5,6]$. More rarely, schizophrenia and other serious mental illnesses may result from mutations with a large impact, such as the translocation that disrupts the gene DISC1 $[7,8]$ and certain copy number variants [9-11]. Through a variety of pathways, these genetic and envi-

\section{KARGER}

E-Mail karger@karger.com www.karger.com/mnp
(C) 2016 S. Karger AG, Basel

2296-9209/16/0023-0133\$39.50/0
Frederick C. Nucifora Jr

Department of Psychiatry, Johns Hopkins University School of Medicine 600 N. Wolfe Street, Meyer 3-161

Baltimore, MD 21287 (USA)

E-Mail nucifora@jhmi.edu 
ronmental risk factors may lead to an imbalance of homeostatic signaling [12], including by disruption of proteostasis (protein quality control), the finely balanced synthesis, folding, and degradation of proteins [13].

Here, we are particularly interested in Neuronal PAS Domain Protein 3 (NPAS3), first associated with schizophrenia after the discovery that a translocation disrupting NPAS3 segregated with a small family with schizophrenia $[14,15]$. Several additional lines of evidence suggest that NPAS3 is relevant to major mental illness. Specific haplotypes of NPAS3 increase the risk for both schizophrenia and bipolar affective disorder (BPAD) [16], and single nucleotide polymorphisms within NPAS3 are associated with iloperidone antipsychotic efficacy [17]. In addition, a meta-analysis of genome-wide association studies identified NPAS3 as one of 226 genes associated with BPAD. NPAS3 was one of only 9 of these genes that were both genetically associated with BPAD and differentially expressed in the dorsolateral prefrontal cortex from individuals with BPAD [18].

NPAS3 is a member of the basic helix-loop-helix (bHLH) family, a group of related proteins involved in regulation of neurogenesis, metabolism, and circadian rhythms [19-21]. NPAS3 contains a bHLH domain (two alpha helices connected by a loop), a PAS domain (named after the three proteins where it was originally identified, period, aryl hydrocarbon receptor and single-minded), and a transcriptional activation domain [22]. The basic helixloop-helix region is involved in DNA binding and dimerization [22]. The affinity of NPAS3-interacting proteins for the PAS domain varies based on environmental and cellular signaling [22]. Mice with targeted disruption of NPAS3, with consequent loss of expression of NPAS3 protein, display behavioral abnormalities that have been associated with schizophrenia $[23,24]$ including reduced prepulse inhibition, hyperactivity, decreased learning and memory, impaired social recognition, and poor maternal nurturing instincts $[23,24]$. In addition, these mice have deficiencies in reelin and defects in hippocampal neurogenesis $[19,23,24]$.

We have previously identified a $\mathrm{G}>\mathrm{A}$ mutation in exon 8 of NPAS3 that segregates with schizophrenia in a small family [25], though the family is too small to statistically associate the mutation with the phenotype. The mutation results in a V304I change in the region between the two PAS domains. This region has been associated with DNA binding capacity, protein stability, and dimerization in two similar proteins, the aryl hydrocarbon nuclear receptor translocator and the dioxin receptor [26]. While valine and isoleucine are both hydrophobic, a va- line to isoleucine mutation in amyloid precursor protein (APP) is a cause of early onset familial Alzheimer's disease [27], in which Lewy bodies were identified in 53\% of these cases [28]. In addition, a valine to isoleucine mutation in transthyretin leads to amyloidosis $[29,30]$, further suggesting a link between valine to isoleucine mutations and abnormal protein conformation and aggregation. Based on these data, we hypothesized that the valine to isoleucine mutation may disrupt NPAS3 protein conformation and lead to NPAS3 aggregation.

In this study, we demonstrate that purified mutant NPAS3 protein expressed in bacteria forms high molecular weight structures, signifying aggregation, much more rapidly than purified wild type (WT) NPAS3. We confirmed this aggregation in a cell-based system, and demonstrate that mutant NPAS3 decreases soluble endogenous (WT) NPAS3, increases insoluble endogenous NPAS3, and leads to altered transcriptional activity. These data indicate the potential of NPAS3 to aggregate, and that mutations increase this propensity, with implications for cell function and disease pathogenesis.

\section{Materials and Methods}

Protein Expression of Bacterially Derived Recombinant Full-Length NPAS3 and Fragments of NPAS3

Full-length WT and NPAS3-V304I cDNA were cloned into a pEX-N-GST vector (Origene) using the $S g f$ and RsrII restriction sites. The NPAS3 fragments were cloned into a pEX-N-HIS-GST vector (Origene). The vectors were transformed into BL21Gold(DE3) competent cells (Agilent Technologies) for protein expression. A single colony was inoculated into a low volume of Luria-Bertani broth and allowed to shake overnight at $37^{\circ} \mathrm{C}, 225 \mathrm{rpm}$. A 1-liter culture was inoculated with the overnight culture and induced with $1.0 \mathrm{~mm}$ IPTG at $\mathrm{OD}_{600}$ of 0.7 for $3 \mathrm{~h}$. The induced culture was harvested at $6,000 \mathrm{~g}$ for $10 \mathrm{~min}$ at $4^{\circ} \mathrm{C}$ and stored at $-80^{\circ} \mathrm{C}$ until ready to perform purification.

\section{Protein Purification Using Affinity Chromatography}

The pellet was resuspended in $1 \times \mathrm{PBS}$, pH 7.3, 1 mM DTT, $1 \mathrm{mM}$ PMSF and $1 \times$ protease inhibitor (Complete; Roche) and lysed by passing twice through the French press at 1,200 psi on ice. The cell suspension was clarified by centrifugation at 15,000 rpm for $15 \mathrm{~min}$ at $4^{\circ} \mathrm{C}$. The lysate was purified by affinity chromatography using a column packed with Glutathione Sepharose 4B resin (GE Healthcare) that had been equilibrated with lysis buffer. The column was washed 3 times with 10 column volumes of lysis buffer without protease inhibitor. In order to elute the protein, the column was incubated with elution buffer (50 mM Tris, $\mathrm{pH} 8.0,20 \mathrm{~mm}$ reduced glutathione, $1 \mathrm{mM} \mathrm{DTT}$ ) for $20 \mathrm{~min}$ and then allowed to flow through and be collected. The eluted protein was then dialyzed against aggregation assay buffer (50 mM Hepes $\mathrm{pH} 8.0,150 \mathrm{mM}$ $\mathrm{NaCl}, 1 \mathrm{~mm}$ EDTA, 8.7\% glycerol). Quantification of protein concentration was done using SDS-PAGE followed by Coomassie staining using bovine serum albumin as a standard. 
Aggregation Assay Studies

Aggregation of the fusion protein was initiated by cleavage of the N-terminal GST or His-GST tag using the ProTEV Plus protease (Promega) according to manufacturer's specifications. To terminate the cleavage reaction, aliquots were collected over a 48hour period and treated with NuPAGE LDS Sample Buffer (Invitrogen). The time point samples were resolved on a NuPAGE 4-12\% Bis-Tris gel (Life Technologies) and transferred to a 0.45 $\mu \mathrm{M}$ PVDF membrane (Immobilon-P; Millipore). NPAS3 peptide antibodies generated against the $\mathrm{N}$-terminal amino acids (AA) 1837 and C-terminal AA 832-847 regions of the full-length NPAS3 protein were used as the primary antibody. An anti-rabbit peroxidase-linked secondary antibody (GE Healthcare) was used at a concentration of $1: 5,000$.

Exogenous NPAS3 Protein Insolubility Studies in Mammalian Cos-1 Cells

Cos-1 cells were transfected with pAAV-Htt-1-171-18QFLAG-ZRBS-hrGFP, pAAV-Htt-1-171-82Q-FLAG-ZRBS-hrGFP, pCMV6 full-length NPAS3-Myc-FLAG, and pCMV6 fulllength NPAS3-V304I-Myc-FLAG at 70\% confluency using a 1:2 DNA to Lipofectine 2000 ratio. Following $48 \mathrm{~h}$ of incubation at $37^{\circ} \mathrm{C}$ and $5 \% \mathrm{CO}_{2}$, the transfected cells were harvested and lysed on ice in lysis buffer [ $50 \mathrm{~mm}$ Hepes, pH 7.5, $300 \mathrm{mM} \mathrm{NaCl}, 250 \mathrm{mM}$ sucrose, $5 \mathrm{~mm}$ EDTA, $5 \mathrm{~mm}$ glutathione (GSH), 1\% NP-40, $0.2 \%$ sarkosyl, $2 \times$ Roche Complete protease inhibitor, $1 \mathrm{mM}$ PMSF] and centrifuged for $1 \mathrm{~h}$ at $1,800 \mathrm{~g}$. Following centrifugation, the resulting supernatant was removed and saved for estimation of protein concentration and gel analysis of the soluble fraction. The pellet was then resuspended on ice in high-salt buffer [50 mM HEPES, pH 7.5, $1.5 \mathrm{M} \mathrm{NaCl}, 250 \mathrm{~mm}$ sucrose, 5 mM EDTA, 5 mM glutathione (GSH), 1\% NP-40, 0.2\% sarkosyl, and $1 \mathrm{mM}$ PMSF] and centrifuged for $1 \mathrm{~h}$ at $1,800 \mathrm{~g}$. The pellet was then resuspended and DNase I treated in $50 \mathrm{~mm}$ Tris, $\mathrm{pH} 8.0,250 \mathrm{~mm}$ sucrose, $5 \mathrm{~mm}$ $\mathrm{MgCl}_{2}, 5 \mathrm{mM}$ GSH, $1 \% \mathrm{NP}-40,2 \times$ Complete protease inhibitor, $1 \mathrm{mM}$ PMSF and DNase I $40 \mathrm{U} / \mathrm{ml}$ and incubated overnight at $4^{\circ} \mathrm{C}$. Samples were then centrifuged at $1,800 \mathrm{~g}$ for $1 \mathrm{~h}$ at $4^{\circ} \mathrm{C}$. The resultant pellet was then resuspended in ice-cold $50 \mathrm{mM}$ Hepes and $0.2 \%$ sarkosyl and ultracentrifuged at $55,000 \mathrm{rpm}$ for $1 \mathrm{~h}$ at $4^{\circ} \mathrm{C}$ in a TLA-100.2 fixed angle rotor. The final pellet was solubilized in $2 \times$ NuPAGE LDS Sample Buffer (Life Technologies) for gel analysis. All pellet samples were analyzed by SDS-PAGE/Western blot analysis. The gels were processed on a NuPAGE 4-12\% Bis-Tris gel (Life Technologies) and transferred to a $0.45 \mu \mathrm{M}$ PVDF membrane (Immobilon-P; Millipore). A monoclonal anti-FLAG M2 antibody produced in mouse (Sigma) was used as the primary antibody for processing the Western blots at a concentration of 1 : 5,000. An anti-mouse peroxidase-linked secondary antibody (GE Healthcare) was used at a concentration of 1:5,000. Quantification of the Western blot was performed using ImageJ Software.

\section{Endogenous NPAS3 Protein Levels}

PAAV-Htt-1-171-18Q-FLAG-ZRBS-hrGFP, pAAV-Htt-1171-82Q-FLAG-ZRBS-hrGFP, pCMV6 full-length NPAS3-MycFLAG, and pCMV6 full-length NPAS3-V304I-Myc-FLAG plasmids were transfected into a 6 -well dish of $\sim 80 \%$ confluent $293 \mathrm{FT}$ cells. Cells were transfected using Lipofectamine 2000 reagent (Life Technologies) at a 1:2 plasmid to Lipofectamine 2000 ratio. The cells were harvested following $48 \mathrm{~h}$ of incubation at $37^{\circ} \mathrm{C}$ and $5 \% \mathrm{CO}_{2}$. The cell pellet was then resuspended in $1 \times \mathrm{PBS}, \mathrm{pH} 7.4$,
$1 \%$ Triton X-100, $1 \times$ Roche Complete protease inhibitor and $1 \mathrm{mM}$ PMSF. The cell suspension was incubated on ice for $20 \mathrm{~min}$ followed by centrifugation at $16,100 \mathrm{~g}$ for $10 \mathrm{~min}$ at $4{ }^{\circ} \mathrm{C}$. Following centrifugation, the supernatant was collected. Total protein quantification of the supernatant sample was determined on the NanoDrop 1000 Spectrophotometer (Thermo Scientific). Supernatant samples were prepared in $1 \times$ NuPAGE LDS Sample Buffer (Life Technologies) for SDS-PAGE/Western blot analysis. The soluble protein samples were resolved on a NuPAGE $4-12 \%$ Bis-Tris gel (Life Technologies) and transferred to a $0.45 \mu \mathrm{M}$ PVDF membrane (Immobilon-P; Millipore). The pellet/insoluble fraction was prepared and processed as described above. An NPAS3 recombinant protein antibody to AA 773-925 was used at a concentration of $1: 1,000$ as the primary antibody to detect endogenous NPAS3 protein. An anti-rabbit peroxidase-linked secondary antibody (GE Healthcare) was used at a concentration of 1:5,000. Quantification of the Western blot was performed using ImageJ Software.

\section{SDS-PAGE/Western Blot Analysis of Cell Death and} Autophagy Markers

293FT cells were transfected using the Lipofectamine 2000 reagent (Life Technologies) at a 1:2 plasmid to Lipofectamine 2000 ratio with pCMV6 full-length NPAS3-FLAG, pCMV6 full-length NPAS3-V304I-FLAG, or pCMV6 alone, and cell samples were collected at $48 \mathrm{~h}$ after transfection. The lysates were processed, and SDS-PAGE/Western blots were performed as described above. Antibodies to poly ADP ribose polymerase (PARP) (Cell Signaling) and microtubule-associated proteins $1 \mathrm{~A} / 1 \mathrm{~B}$ light chain $3 \mathrm{~A}$ (LC3) (Cell Signaling) were used at a concentration of 1:1,000. Quantification of the Western blot was performed using ImageJ Software.

\section{Luciferase Assay in 293FT Cells}

A $5^{\prime}$ human VGF sequence $(2,029 \mathrm{~kb})$, containing promoter, exon1, intron1 and part of exon2, was amplified by PCR and cloned into digested pGL3 reporter vectors. 293FT cells were transfected with pCMV6 full-length NPAS3-FLAG, pCMV6 fulllength NPAS3-V304I-FLAG, or p CMV6 alone, and cell samples were collected at $48 \mathrm{~h}$ after transfection. The firefly luciferase activity was measured from each sample using the Promega luciferase assay system with the Fluoroskan Ascent FL Microplate Fluorometer and Luminometer. For each sample, the firefly luciferase activity was normalized to the vector control.

\section{Results}

\section{Bacterially Derived Recombinant NPAS3 Fusion Proteins}

The constructs used for bacterial expression were designed with an N-terminal GST tag to facilitate the purification of soluble protein under native conditions (see schematic, fig. 1a). Purified WT NPAS3 or purified NPAS3-V304I (fig. 1b, left and c, left) were detected at $125 \mathrm{kDa}$ (black arrow), corresponding to the predicted size of full-length NPAS3 $(\sim 100 \mathrm{kDa})$ with a GST tag $(\sim 25 \mathrm{kDa})$. The other bands detected by Coomassie stain- 


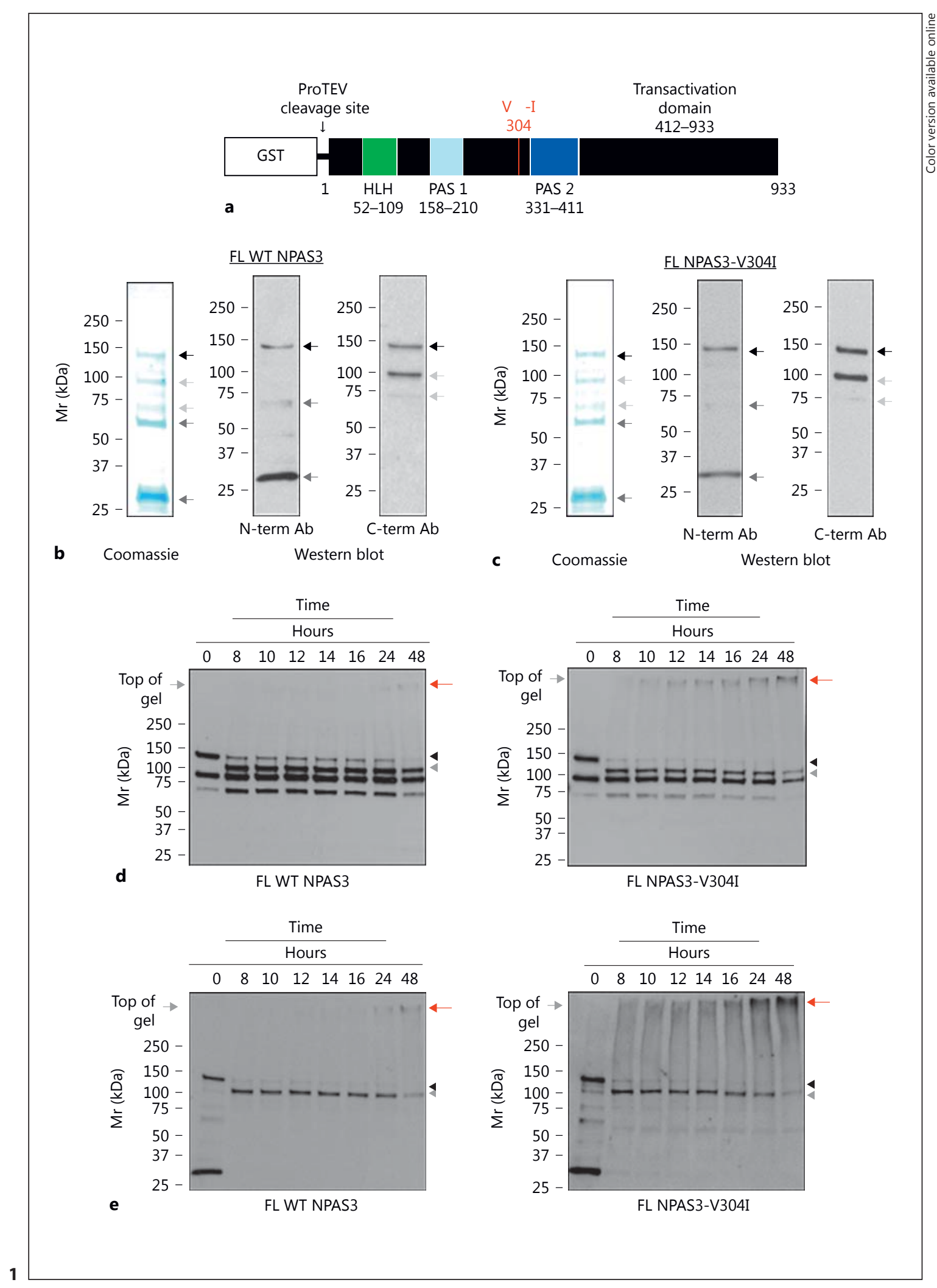

(For legend see next page.) 
ing (gray arrows) represent potential cleavage products of NPAS3. Western blot analysis of the purified fusion GSTprotein (fig. $1 \mathrm{~b}$, right and $\mathrm{c}$, right) showed reactivity to antibodies generated against the $\mathrm{N}$-terminus and $\mathrm{C}$-terminus of full-length NPAS3, confirming the identity of the $125-\mathrm{kDa}$ band. The other bands detected match the Coomassie staining and suggest various $\mathrm{N}$-terminal (dark gray arrows) and C-terminal (light gray arrows) cleavage products.

\section{The V304I Mutation in Purified NPAS3 Increases Aggregation}

An aggregation assay was performed using purified recombinant GST-tagged fusion proteins to compare the propensity of WT NPAS3 and NPAS3-V304I to aggregate. The fusion proteins were treated with ProTEV Plus protease to cleave the N-terminal GST tag and release the full-length monomeric protein, initiating aggregation. The cleavage reaction was allowed to proceed for up to 48 hours. Western blots using a C-terminal NPAS3 antibody (fig. 1d) showed NPAS3 with an intact GST tag at $125 \mathrm{kDa}$ (black arrowhead) at time 0 . After cleavage of the GST tag from NPAS3-V304I, SDS-insoluble protein accumulated at the bottom of the loading slots/top of the gel (red arrow) by 8 hours (fig. 1d right), and continued to accumulate until the majority of the $\sim 100-\mathrm{kDa}$ monomeric species (gray arrowhead) was undetectable. In contrast, accumulation of SDS-resistant protein (red arrow) (fig. 1d left) did not occur until the 16-hour time point after cleavage of the GST tag from WT NPAS3, and was not clearly evident until the 24 -hour time point. The full blots are shown in these figures with the insoluble protein accumulating at the bottom of the loading slot/top of the gel (red arrow). In addition, an approximately $70-\mathrm{kDa}$ band was detected that decreased over time, likely an NPAS3 cleavage product that also aggregates, consistent with cleavage-enhanced aggregation detected in other aggregation-prone proteins [31]. The same pattern of loss of monomeric and increase in insoluble NPAS3 was observed using the N-terminal antibody to NPAS3 (fig. 1e), except that the $70-\mathrm{kDa}$ band was not detected. These data together suggest that the V304I mutation enhances aggregation of the NPAS3 protein.

\section{The Region between the PAS Domains Is Critical for NPAS3 Aggregation}

In order to identify the region within full-length WT NPAS3 most relevant to initiating aggregation, fusion constructs specific to the various domains of NPAS3 were expressed and purified, and subjected to the same aggregation assay as described above, with detection using the $\mathrm{N}$-terminal antibody (fig. 2). The fragments that included the HLH domain (AA 1-109) (fig. 2a) and the HLH and first PAS1 domain (AA 1-210) (fig. 2b) did not form distinct SDS-resistant insoluble aggregates at any point throughout the 24-hour time course. In contrast, the fragment containing the HLH, the first PAS1 domain, and the region up to the second PAS domain (AA 1-331) (fig. 2c), and the fragment containing the HLH and both PAS domains (AA 1-411) (fig. 2d), all formed SDS-resistant insoluble aggregates (red arrow) that accumulated at the bottom of the loading slot/top of the gel. Both of these
Fig. 1. The V304I mutation in purified NPAS3 increases aggregation. a Schematic representation of bacterially derived full-length NPAS3 as a GST fusion protein and its functional domains. Major functional domains include the helix-loop-helix (HLH) domain (green), the PAS1 domain (light blue) and the PAS2 domain (blue). The GST tag (gray; not drawn to scale) is located on the N-terminus of the protein followed by the ProTEV cleavage site. The V304I mutation is indicated as a red line (colors refer to the online version only). b SDS-PAGE/Coomassie analysis of GST-full-length WT NPAS3 and Western blot analysis of purified GST-full-length WT NPAS3 using an N-terminal antibody specific to NPAS3 and C-terminal antibody specific to NPAS3. c SDS-PAGE/Coomassie analysis and Western blot analysis of GST-full-length NPAS3V304I. For both $\mathbf{b}$ and $\mathbf{c}$, purified WT NPAS3 or purified NPAS3V304I were detected at $125 \mathrm{kDa}$ (black arrow), corresponding to the predicted size of full-length NPAS3 $(\sim 100 \mathrm{kDa})$ with a GST tag $(\sim 25 \mathrm{kDa})$. The other bands represent NPAS3 cleavage products, with $\mathrm{N}$-terminal cleavage fragments represented by dark gray arrows and C-terminal cleavage fragments by light gray arrows. This demonstrates that we successfully purified NPAS3. d, e In vitro aggregation assay of WT and mutant full-length NPAS3. Cleavage of the N-terminal GST tag initiates aggregation. Time points were collected over 48 hours and analyzed by SDS-PAGE followed by Western blotting. $\mathbf{d}$ Western blot analysis of the aggregation time course for GST-full-length NPAS3 (left panel) and GST-fulllength NPAS3-V304I (right panel) using a C-terminal NPAS3 antibody. e Western blot analysis of the aggregation time course for GST-full-length NPAS3 (left panel) and GST-full-length NPAS3V304I (right panel) using an N-terminal NPAS3 antibody. For both $\mathbf{d}$ and $\mathbf{e}$, SDS-resistant aggregates are indicated as a red arrow at the top of the blot, corresponding to the bottom of the loading slot. Fusion protein is indicated as a black arrowhead and cleaved monomer as a gray arrowhead for all Western blots. These data demonstrate that NPAS3 is prone to forming insoluble complexes, reflecting multimeric NPAS3 aggregates, and that the V304I mutation in NPAS3 greatly enhances this process. Purification and Western blots were repeated with similar results. 


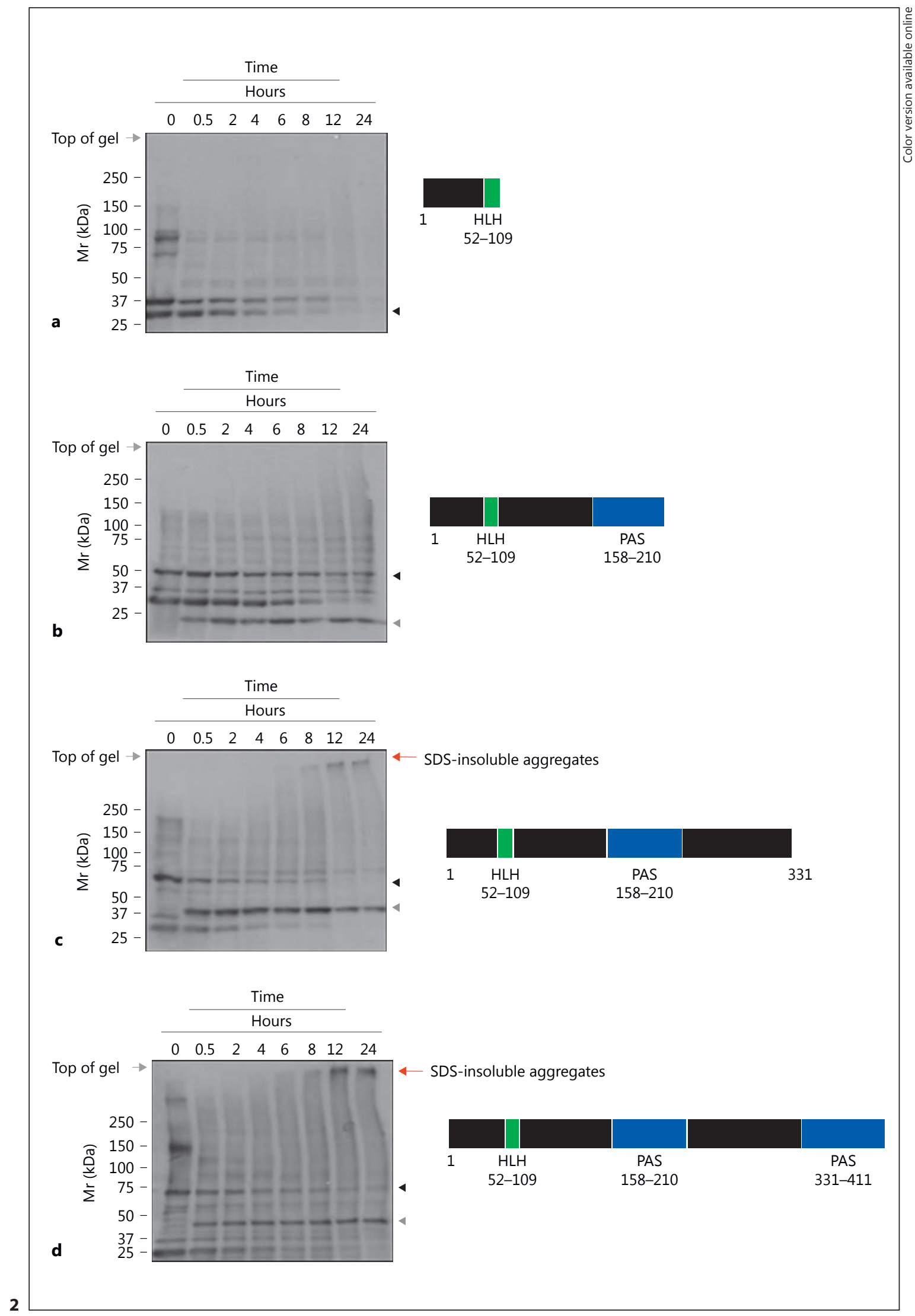

(For legend see next page.) 


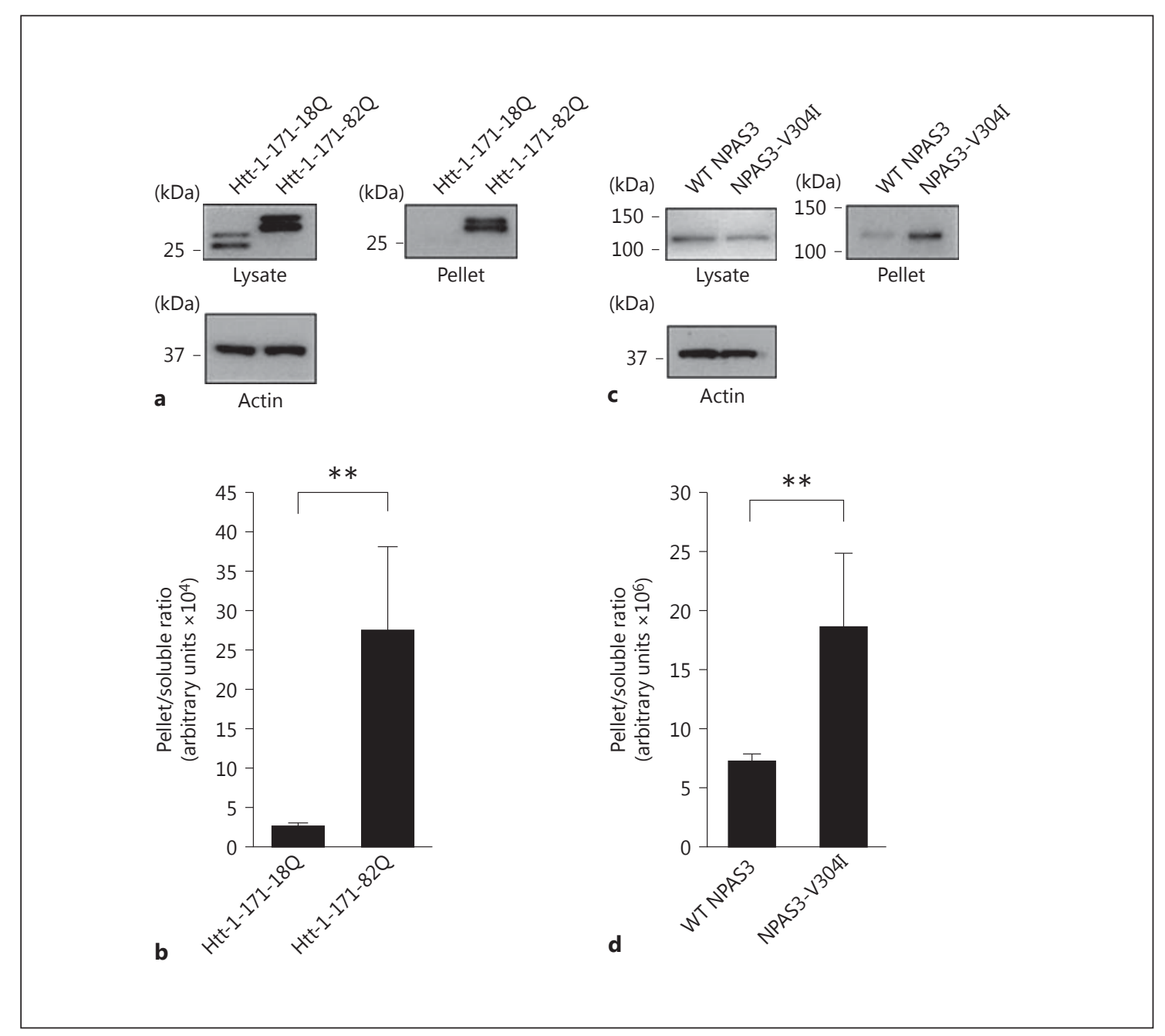

Fig. 3. NPAS3 aggregation is increased by V304I in a mammalian expression system. In order to investigate NPAS3 aggregation in mammalian cells, we expressed WT NPAS3, NPAS3-V304I, Htt1-171-18Q (negative control) and Htt-1-171-82Q (positive control) in Cos- 1 cells and performed a cell fractionation protocol that yields a purified soluble (lysate) and insoluble (pellet) protein fraction. a SDS-PAGE/Western blot analysis showing representative soluble (lysate) and insoluble (pellet) fractions for Htt-1-171-18Q (negative control) and Htt-1-171-82Q (positive control). b Quan- tification of a. As predicted, Htt 1-171-82Q, but not Htt-1-171$18 \mathrm{Q}$, was enriched in the pellet (insoluble fraction) after fractionation. c SDS-PAGE/Western blot analysis showing representative soluble (lysate) and insoluble (pellet) fractions for WT NPAS3 and NPAS3-V304I. d Quantification of c. These data show that WT NPAS3 is prone to aggregate in mammalian cells and that V304I substantially increases aggregation. All experiments were independently performed at least three times, where data are the mean \pm SD. ${ }^{* *} \mathrm{p}<0.001$ using a one-way ANOVA test.
Fig. 2. The region between the PAS domains is critical for NPAS3 aggregation. In vitro aggregation assay of NPAS3 fragments. Cleavage of the N-terminal His-GST tag initiates aggregation. Time points were collected over a 24-hour time course and analyzed using SDS-PAGE followed by Western blotting using an Nterminal antibody for NPAS3. The Western blots and domain schematic for the aggregation assay performed are shown for AA 1-109 (a), AA 1-210 (b), AA 1-331 (c), and AA 1-411 (d). SDSinsoluble aggregates (red arrow) were only observed in assays per- formed with $\mathrm{N}$-terminal fragments that included the region between the two PAS domains $(\mathbf{c}, \mathbf{d})$ where the mutation is located (colors refer to the online version only). The fusion protein is indicated as a black arrowhead, and the cleaved monomer protein is indicated as a gray arrowhead. These data suggest that the unstructured domain between the two PAS domains, where AA 304 is located, contains the critical structural components in initiating aggregation in the NPAS3 protein. Purification and Western blots were repeated with similar results. 


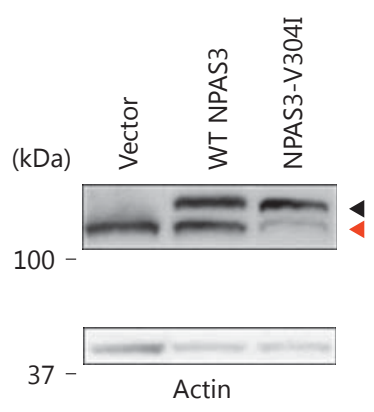

a

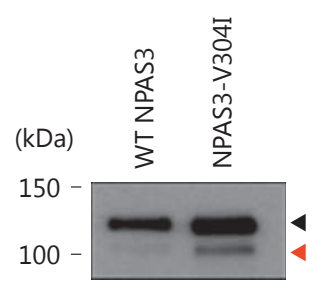

d
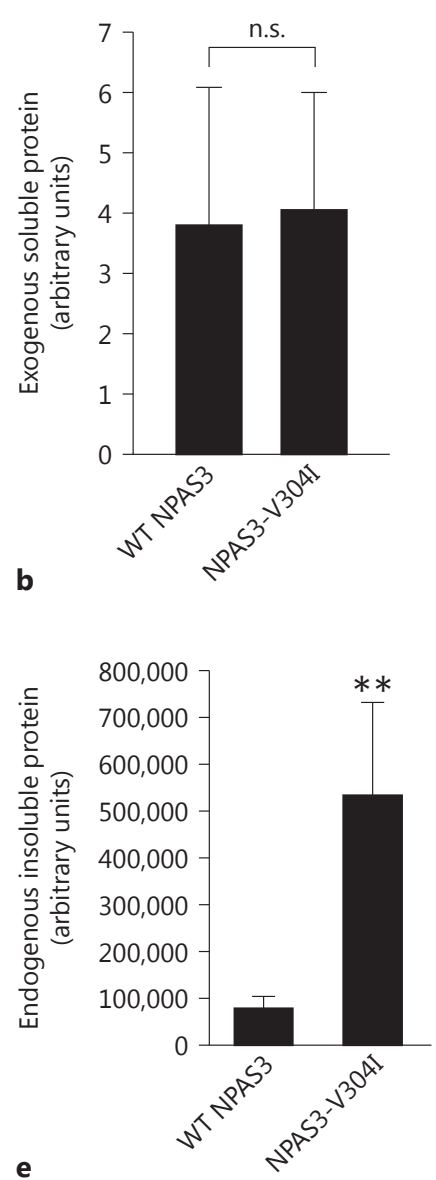

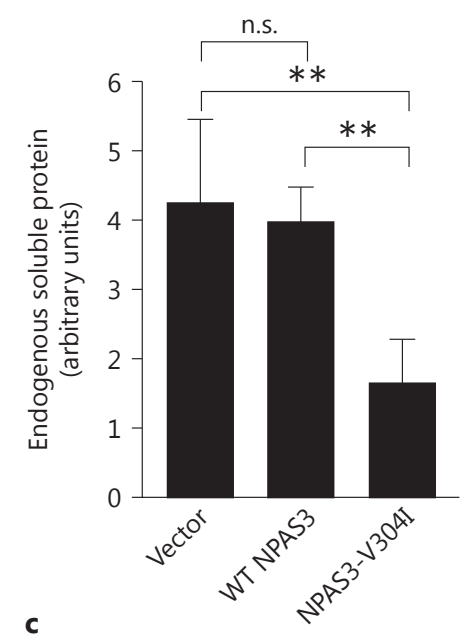

C

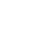

Fig. 4. Exogenous NPAS3-V304I reduces the levels of soluble endogenous NPAS3 and increases insoluble endogenous NPAS3. a Vector, WT NPAS3, or NPAS3-V304I were separately transfected into HEK293 cells, and the levels of endogenous and transfected NPAS3 protein were measured by Western blot. Black arrowhead indicates exogenous WT NPAS3 and NPAS3-V304I proteins present in the supernatant. Red arrowhead indicates endogenous NPAS3 protein. $\mathbf{b}$ Quantification of the levels of exogenous WT NPAS3 and NPAS3-V304I, demonstrating that they were expressed at similar levels. c Quantification of endogenous NPAS3 protein levels as detected by Western blot and ImageJ analysis.

constructs include AA 304, where the substitution occurs in the mutant form of the protein. These data suggest that the unstructured domain between the two PAS domains, where AA 304 is located, contains the critical structural components in initiating aggregation in the NPAS3 protein.
NPAS3-V304I significantly decreased endogenous NPAS3 compared to empty vector or WT NPAS3. d The levels of endogenous NPAS3 were analyzed in the pellet fraction by Western blot when WT NPAS3 or NPAS3-V304I were separately transfected. NPAS3V304I significantly increased endogenous NPAS3 compared to WT NPAS3. This suggests that NPAS3-V304I sequesters endogenous NPAS3. Red arrowhead indicates endogenous NPAS3 protein. All experiments were independently performed at least three times, where data are the mean \pm SD. ${ }^{* *} \mathrm{p}<0.001$, one-way ANOVA test.

\section{NPAS3 Aggregation Is Dramatically Augmented by V304I in a Mammalian Expression System}

In order to investigate NPAS3 aggregation in mammalian cells, we expressed WT NPAS3 and NPAS3-V304I in Cos- 1 cells and performed a cell fractionation protocol that yields a purified insoluble protein fraction. Hunting- 
tin fragments Htt-1-171-18Q and Htt-1-171-82Q were used as negative and positive controls respectively (fig. 3a, b), since it is well established that the huntingtin protein with an unexpanded polyglutamine repeat has little ability to aggregate, but aggregation occurs when huntingtin contains an expanded glutamine repeat. As predicted, Htt-1-171-82Q, but not Htt-1-171-18Q, was detected in the pellet (insoluble fraction) after fractionation (fig. 3a, b). The amount of insoluble NPAS3-V304I was markedly greater than that for WT NPAS3 (fig. 3c, d). We conclude that while WT NPAS3 is prone to aggregate in mammalian cells, V304I substantially increases aggregation.

Exogenous NPAS3-V304I Reduces Soluble Levels

of Endogenous NPAS3 and Increases Insoluble

Endogenous NPAS3

To determine whether NPAS3-V304I can affect endogenous NPAS3, empty vector, WT NPAS3 and NPAS3V304I were separately transfected into HEK293 cells. Levels of endogenous and transfected NPAS3 protein were measured after 48 hours by Western blot using a recombinant protein antibody that recognizes both exogenous and endogenous NPAS3. Expression levels of exogenous WT NPAS3 and NPAS3-V304I were similar (black arrowhead) (fig. 4a, b). NPAS3-V304I significantly decreased endogenous NPAS3 compared to empty vector or WT NPAS3 (red arrowhead) (fig. 4a, c). Western blot analysis of the pellet fraction of transfected cells demonstrated that exogenous NPAS3-V304I increases insoluble endogenous NPAS3 (red arrowhead) (fig. 4d, e), suggesting that NPAS3-V304I is sequestering endogenous NPAS3.

Mutant NPAS3 Does Not Cause Cellular Death, but Does Interfere with the Transcriptional Function of NPAS3

To determine whether NPAS3-V304I increased markers of cell death, empty vector, WT NPAS3 and NPAS3V304I were separately transfected into HEK293 cells, and levels of PARP and microtubule-associated proteins 1A/1B LC3 were measured after 48 hours by Western blot. We did not see any difference in the levels of either marker (fig. 5a-d), suggesting that NPAS3-V304I does not lead to cell death. To determine if the mutation might have a more subtle impact on cell function in this same cell system, we examined the effect of the mutation on the transcriptional activity of NPAS3 using an assay in which expression of a luciferase reporter construct is driven by the promoter for VGF, a known target of NPAS3 [20]. As predicted by our model, NPAS3-V304I aggregates and therefore loses its capacity to activate transcription. VGF transcription was activated to a significantly greater extent by transfected WT NPAS3 than by transfected NPAS3-V304I (fig. 5e), providing a potential mechanism by which NPAS3-V304I may lead to cell dysfunction.

\section{Discussion}

We demonstrate, using purified protein and a mammalian cell expression system, that NPAS3 is prone to forming insoluble complexes, reflecting multimeric NPAS3 aggregates, and that the V304I mutation in NPAS3 greatly enhances this process. To our knowledge, this is the first report of a point mutation associated with schizophrenia or bipolar disorder that can lead to protein aggregation. We also demonstrate that NPAS3-V304I reduces levels of soluble endogenous NPAS3 and increases insoluble endogenous NPAS3, and that NPAS3-V304I is less effective than WT NPAS3 in driving transcription. Taken together, these data suggest that the NPAS3 V304I mutation enhances aggregation of monomeric full-length and cleaved mutant and endogenous WT NPAS3, leading to a loss of NPAS3 transcriptional activity via sequestration.

The explanation for NPAS3 aggregation, and the enhanced aggregation of NPAS3 V304I, is not immediately apparent, though our data suggest that the region between the two PAS domains is critical to the formation of aggregates. Mutations are well known to have the capacity to destabilize monomeric forms of a protein, facilitating amyloidogenic intermediates [32]. More generally, oxidative stress and other stress cascades, implicated in the pathogenesis of many diseases of the central nervous system including schizophrenia [33], can lead to protein misfolding [34].

The relationship between aggregation and neurotoxicity (defined broadly to include both cell death and cell dysfunction) has been intensely explored [35-38]. We propose that the aggregation process confers neurodysfunction by sequestration of NPAS3. While the aggregate itself may not be toxic, and could reflect a protective mechanism for the cell to handle deleterious misfolded proteins $[35,39,40]$, the aggregation process signifies, or marks, an underlying pathological process. The nature of the pathological process may differ from one disease to another, but could include toxicity of pre-aggregate protein intermediate species $[31,35]$, or a general disruption of protein homeostasis that results in failure of mechanisms that normally check abnormal protein folding [13, 

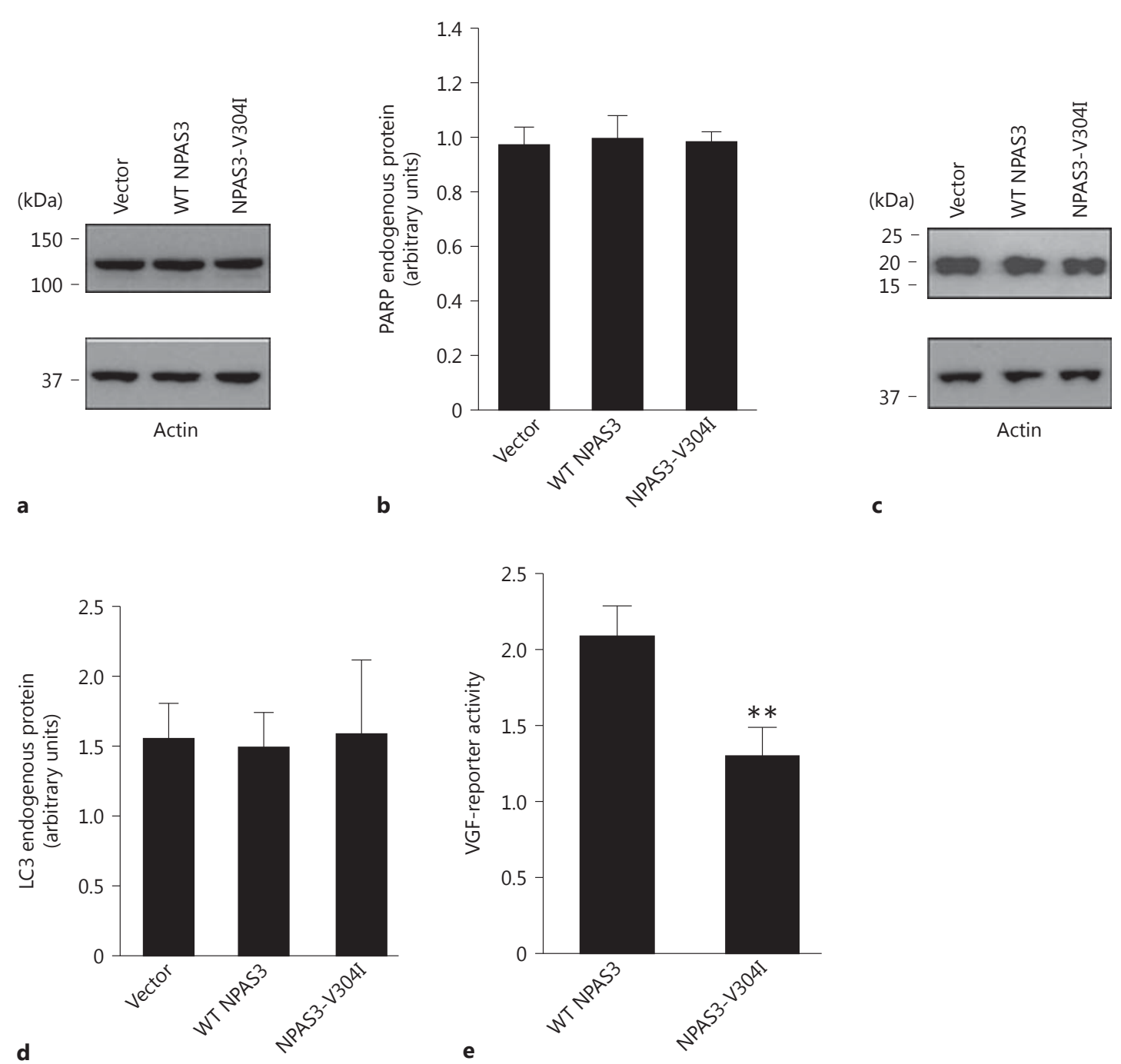

Fig. 5. Mutant NPAS3 does not lead to cellular death, but does interfere with the function of NPAS3. a Empty vector, WT NPAS3, or NPAS3-V304I were separately transfected into HEK293 cells, and levels of PARP were measured after $48 \mathrm{~h}$ by Western blot. b Quantification of a. c Empty vector, WT NPAS3, or NPAS3-V304I were separately transfected into HEK293 cells, and levels of LC3 were measured after 48 hours by Western blot. $\mathbf{d}$ Quantification of c. We did not see any difference in the levels of either of these pro- teins, suggesting that NPAS3-V304I does not cause cellular death. e Luciferase assay using the promoter for VGF, a gene known to be activated by NPAS3. These data show that NPAS3-V304I has significantly less ability to activate transcription of VGF than WT NPAS3, suggesting that the mutation interferes with the function of NPAS3, likely through sequestration of endogenous NPAS3. All experiments were independently performed at least three times, where data are the mean $\pm \mathrm{SD} .{ }^{* *} \mathrm{p}<0.001$, one-way ANOVA test.
41, 42]. Alternatively, aggregation of a mutant protein could itself lead to disruption of protein quality control mechanisms.

The properties of NPAS3 elucidated in our experiments have intriguing analogies with the properties of DISC1. Like NPAS3, DISC1 may be prone to aggregation
[43-46]. This tendency to aggregate may be relevant to psychiatric disease, as DISC1 aggregates were reported to occur more frequently in post-mortem brain samples from individuals with depression, bipolar disorder, and schizophrenia than in controls [43]. Mechanistically, DISC1 aggregation has been associated with altered do- 
pamine homeostasis in a rat model [44], perhaps related to sequestration of DISC1 itself or of other proteins sequestered along with DISC1 (e.g., dysbindin) [45]. Loss of DISC1 is also associated with a decrease in VGF expression, of interest here given the potential loss of VGF expression following loss of NPAS3 [47].

Protein aggregation is a common finding in many neurodegenerative diseases (including Huntington's disease, Parkinson's disease, and Alzheimer's disease) [31, 36]. Our results provide additional evidence, in support of earlier findings in DISC1, that protein aggregation, and more broadly, disruption of protein homeostasis and quality control, may contribute to the pathogenesis of at least a subset of patients with major mental illness. This concept suggests that determining the frequency and scope of abnormal protein homeostasis and quality control in brain samples from individuals with mental illness, and in cell and animal models of these diseases, has the potential to yield novel pathways and therapeutic targets.

\section{Statement of Ethics}

The authors have no ethical conflicts to disclose.

\section{Disclosure Statement}

The authors of the paper do not have any conflicts of interest.

\section{References}

1 Perala J, Suvisaari J, Saarni SI, Kuoppasalmi K, Isometsa E, Pirkola S, Partonen T, TuulioHenriksson A, Hintikka J, Kieseppa T, Harkanen T, Koskinen S, Lonnqvist J: Lifetime prevalence of psychotic and bipolar I disorders in a general population. Arch Gen Psychiatry 2007;64:19-28.

2 Purcell SM, Wray NR, Stone JL, Visscher PM, O’Donovan MC, Sullivan PF, Sklar P: Common polygenic variation contributes to risk of schizophrenia and bipolar disorder. Nature 2009;460:748-752.

3 Ripke S, O’Dushlaine C, Chambert K, Moran $\mathrm{JL}$, et al: Genome-wide association analysis identifies 13 new risk loci for schizophrenia. Nat Genet 2013;45:1150-1159.

4 Purcell SM, Moran JL, Fromer M, Ruderfer D, et al: A polygenic burden of rare disruptive mutations in schizophrenia. Nature 2014;506: 185-190.

5 Kendler KS, Eaves LJ: Models for the joint effect of genotype and environment on liability to psychiatric illness. Am J Psychiatry 1986; 143:279-289.

6 Rutter M, Moffitt TE, Caspi A: Gene-environment interplay and psychopathology: multiple varieties but real effects. J Child Psychol Psychiatry 2006;47:226-261.

7 St Clair D, Blackwood D, Muir W, Carothers A, Walker M, Spowart G, Gosden C, Evans HJ: Association within a family of a balanced autosomal translocation with major mental illness. Lancet 1990;336:13-16.

8 Brandon NJ, Sawa A: Linking neurodevelopmental and synaptic theories of mental illness through DISC1. Nat Rev Neurosci 2011;12: 707-722.

9 Stefansson H, Rujescu D, Cichon S, Pietilainen OP, et al: Large recurrent microdeletions associated with schizophrenia. Nature 2008; 455:232-236.
10 Kirov G, Pocklington AJ, Holmans P, Ivanov $D$, et al: De novo CNV analysis implicates specific abnormalities of postsynaptic signalling complexes in the pathogenesis of schizophrenia. Mol Psychiatry 2012;17:142-153.

11 MacIntyre DJ, Blackwood DH, Porteous DJ, Pickard BS, Muir WJ: Chromosomal abnormalities and mental illness. Mol Psychiatry 2003;8:275-287.

12 Landek-Salgado MA, Faust TE, Sawa A: Molecular substrates of schizophrenia: homeostatic signaling to connectivity. Mol Psychiatry 2016;21:10-28.

13 Hipp MS, Park SH, Hartl FU: Proteostasis impairment in protein-misfolding and -aggregation diseases. Trends Cell Biol 2014;24:506514.

14 Kamnasaran D, Muir WJ, Ferguson-Smith MA, Cox DW: Disruption of the neuronal PAS3 gene in a family affected with schizophrenia. J Med Genet 2003;40:325-332.

15 Pickard BS, Malloy MP, Porteous DJ, Blackwood DH, Muir WJ: Disruption of a brain transcription factor, NPAS3, is associated with schizophrenia and learning disability. Am J Med Genet B Neuropsychiatr Genet 2005; 136b:26-32.

16 Pickard BS, Christoforou A, Thomson PA, Fawkes A, Evans KL, Morris SW, Porteous DJ, Blackwood DH, Muir WJ: Interacting haplotypes at the NPAS3 locus alter risk of schizophrenia and bipolar disorder. Mol Psychiatry 2009; 14:874-884

17 Lavedan C, Licamele L, Volpi S, Hamilton J, Heaton C, Mack K, Lannan R, Thompson A, Wolfgang CD, Polymeropoulos MH: Association of the NPAS3 gene and five other loci with response to the antipsychotic iloperidone identified in a whole genome association study. Mol Psychiatry 2009;14:804-819.
18 Nurnberger JI Jr, Koller DL, Jung J, Edenberg HJ, Foroud T, Guella I, Vawter MP, Kelsoe JR: Identification of pathways for bipolar disorder: a meta-analysis. JAMA Psychiatry 2014; 71:657-664.

19 Pieper AA, Wu X, Han TW, Estill SJ, Dang Q Wu LC, Reece-Fincanon S, Dudley CA, Richardson JA, Brat DJ, McKnight SL: The neuronal PAS domain protein 3 transcription factor controls FGF-mediated adult hippocampal neurogenesis in mice. Proc Natl Acad Sci USA 2005; 102:14052-14057.

20 Sha L, MacIntyre L, Machell JA, Kelly MP, Porteous DJ, Brandon NJ, Muir WJ, Blackwood DH, Watson DG, Clapcote SJ, Pickard BS: Transcriptional regulation of neurodevelopmental and metabolic pathways by NPAS3 . Mol Psychiatry 2012;17:267-279.

21 Stanco A, Pla R, Vogt D, Chen Y, Mandal S, Walker J, Hunt RF, Lindtner S, Erdman CA, Pieper AA, Hamilton SP, Xu D, Baraban SC, Rubenstein JL: NPAS1 represses the generation of specific subtypes of cortical interneurons. Neuron 2014;84:940-953.

22 Brunskill EW, Witte DP, Shreiner AB, Potter SS: Characterization of npas3, a novel basic helix-loop-helix PAS gene expressed in the developing mouse nervous system. Mech Dev 1999;88:237-241.

23 Erbel-Sieler C, Dudley C, Zhou Y, Wu X, Estill SJ, Han T, Diaz-Arrastia R, Brunskill EW, Potter SS, McKnight SL: Behavioral and regulatory abnormalities in mice deficient in the NPAS1 and NPAS3 transcription factors. Proc Natl Acad Sci USA 2004;101:1364813653.

24 Brunskill EW, Ehrman LA, Williams MT, Klanke J, Hammer D, Schaefer TL, Sah R, Dorn GW, 2nd, Potter SS ,Vorhees CV: Abnormal neurodevelopment, neurosignaling and behaviour in Npas3-deficient mice. Eur J Neurosci 2005;22:1265-1276. 
25 Yu L, Arbez N, Nucifora LG, Sell GL, Delisi LE, Ross CA, Margolis RL, Nucifora FC Jr: A mutation in NPAS3 segregates with mental illness in a small family. Mol Psychiatry 2014; 19:7-8.

26 Chapman-Smith A, Whitelaw ML: Novel DNA binding by a basic helix-loop-helix protein. The role of the dioxin receptor PAS domain. J Biol Chem 2006;281:12535-12545.

27 Mullan M, Tsuji S, Miki T, Katsuya T, Naruse S, Kaneko K, Shimizu T, Kojima T, Nakano I, Ogihara T, et al: Clinical comparison of Alzheimer's disease in pedigrees with the codon 717 Val->Ile mutation in the amyloid precursor protein gene. Neurobiol Aging 1993;14: 407-419.

28 Rosenberg CK, Pericak-Vance MA, Saunders AM, Gilbert JR, Gaskell PC, Hulette CM: Lewy body and Alzheimer pathology in a family with the amyloid-beta precursor protein APP717 gene mutation. Acta Neuropathol 2000;100:145-152.

29 Jenne DE, Denzel K, Blatzinger P, Winter P, Obermaier B, Linke RP, Altland K: A new isoleucine substitution of Val-20 in transthyretin tetramers selectively impairs dimer-dimer contacts and causes systemic amyloidosis. Proc Natl Acad Sci USA 1996;93:6302-6307.

30 Connors LH, Lim A, Prokaeva T, Roskens VA, Costello CE: Tabulation of human transthyretin (TTR) variants. Amyloid 2003;10: 160-184.

31 Ross CA, Poirier MA: Protein aggregation and neurodegenerative disease. Nat Med 2004;10(suppl):S10-S17.

32 Kelly JW: Alternative conformations of amyloidogenic proteins govern their behavior. Curr Opin Struct Biol 1996;6:11-17.
33 Emiliani FE, Sedlak TW, Sawa A: Oxidative stress and schizophrenia: recent breakthroughs from an old story. Curr Opin Psychiatry 2014;27:185-190.

34 Grune T, Jung T, Merker K, Davies KJ: Decreased proteolysis caused by protein aggregates, inclusion bodies, plaques, lipofuscin, ceroid, and 'aggresomes' during oxidative stress, aging, and disease. Int J Biochem Cell Biol 2004;36:2519-2530.

35 Stefani M, Dobson CM: Protein aggregation and aggregate toxicity: new insights into protein folding, misfolding diseases and biological evolution. J Mol Med 2003;81:678-699.

36 Ross CA, Poirier MA: What is the role of protein aggregation in neurodegeneration? Nat Rev Mol Cell Biol 2005;6:891-898.

37 Winklhofer KF, Tatzelt J, Haass C: The two faces of protein misfolding: gain- and lossof-function in neurodegenerative diseases. EMBO J 2008;27:336-349.

38 Olzscha H, Schermann SM, Woerner AC, Pinkert S, Hecht MH, Tartaglia GG, Vendruscolo M, Hayer-Hartl M, Hartl FU, Vabulas RM: Amyloid-like aggregates sequester numerous metastable proteins with essential cellular functions. Cell 2011;144:67.

39 Takalo M, Salminen A, Soininen H, Hiltunen M, Haapasalo A: Protein aggregation and degradation mechanisms in neurodegenerative diseases. Am J Neurodegener Dis 2013;2: $1-14$.

40 Nucifora FC Jr, Nucifora LG, Ng C-H, Arbez N, Guo Y, Roby E, Shani V, Engelender S, Wei D, Wang X-F, Li T, Moore DJ, Pletnikova O, Troncoso JC, Sawa A, Dawson TM, Smith W, Lim K-H, Ross CA: Ubiquitination via K27 and $\mathrm{K} 29$ chains signals aggregation and neuronal protection of LRRK2 by WSB1. Nat Commun 2016;7:11792.
41 Chiti F, Dobson CM: Protein misfolding, functional amyloid, and human disease. Annu Rev Biochem 2006;75:333-366.

42 Gestwicki JE, Garza D: Protein quality control in neurodegenerative disease. Prog Mol Biol Transl Sci 2012;107:327-353.

43 Leliveld SR, Bader V, Hendriks P, Prikulis I, Sajnani G, Requena JR, Korth C: Insolubility of disrupted-in-schizophrenia 1 disrupts oligomer-dependent interactions with nuclear distribution element 1 and is associated with sporadic mental disease. J Neurosci 2008;28:3839-3845.

44 Trossbach SV, Bader V, Hecher L, Pum ME, et al: Misassembly of full-length Disruptedin-Schizophrenia 1 protein is linked to altered dopamine homeostasis and behavioral deficits. Mol Psychiatry DOI: 10.1038/mp.2015. 194.

45 Ottis P, Bader V, Trossbach SV, Kretzschmar H, Michel M, Leliveld SR, Korth C: Convergence of two independent mental disease genes on the protein level: recruitment of dysbindin to cell-invasive disrupted-in-schizophrenia 1 aggresomes. Biol Psychiatry 2011; 70:604-610.

46 Korth C: Aggregated proteins in schizophrenia and other chronic mental diseases: DISC1opathies. Prion 2012;6:134-141.

47 Ramos A, Rodríguez-Seoane C, Rosa I, Trossbach SV, Ortega-Alonso A, Tomppo L, Ekelund J, Veijola J, Järvelin M-R, Alonso J, Veiga S, Sawa A, Hennah W, García A, Korth C, Requena JR: Neuropeptide precursor VGF is genetically associated with social anhedonia and underrepresented in the brain of major mental illness: its downregulation by DISC1. Hum Mol Genet 2014;23:5859-5865. 